\title{
Optimizing citrate dose for regional anticoagulation in continuous renal replacement therapy: measuring citrate concentrations instead of ionized calcium?
}

\author{
Patrick M. Honore*, Rita Jacobs, Inne Hendrickx, Elisabeth De Waele, Viola Van Gorp and Herbert D. Spapen \\ See related research by Schwarzer et al., http://www.ccforum.com/content/19/1/321
}

Regular measurement of systemic and post-filter ionized calcium (iCa) concentrations is imperative to correctly handle regional citrate anticoagulation dose during continuous renal replacement therapy (CRRT). Keeping post-filter iCa within a tight range guarantees optimal circuit function and enhances filter life span $[1,2]$, whereas a decrease in plasma $\mathrm{iCa}$, with subsequent elevation of the total-to-ionized plasma calcium ratio, can predict systemic citrate accumulation [3].

The new findings (published recently in Critical Care) of Schwarzer et al. expose an alarming inaccuracy for measuring post-filter iCa with currently available blood gas analyzers [4]. This precludes adequate control of citrate flow and raises evident functional and safety issues. On the other hand, Schwarzer et al. found good concordance between all evaluated analyzers for measuring systemic $\mathrm{iCa}$ levels [4]. However, the total-to-ionized plasma calcium ratio has occasionally been shown to be a relatively weak indirect marker for citrate accumulation or intoxication [1,2]. Direct measurement of citrate systemic concentrations could overcome these iCarelated shortcomings. In this perspective, compelling evidence was provided by Italian investigators who adapted a commercially available citrate analyzing kit for measuring systemic and also filter citrate concentrations [5]. Preliminary experience in septic shock patients with liver dysfunction undergoing CRRT suggested a potential clinical use but needs confirmation in a larger and more heterogeneous patient population.

\section{Abbreviations}

CRRT: Continuous renal replacement therapy; iCa: lonized calcium.

\section{Competing interests}

The authors declare that they have no competing interests.

\section{Authors' contributions}

PMH and HDS designed and helped draft the manuscript. RJ, IH, EDW and WG helped draft the manuscript. All authors read and approved the final manuscript.

Published online: 06 November 2015

\section{References}

1. Egi M, Naka T, Bellomo R, Cole L, French C, Trethewy C, et al. A comparison of two citrate anticoagulation regimens for continuous veno-venous hemofiltration. Int J Artif Organs. 2005;28:1211-8.

2. Jacobs R, Honoré PM, Bagshaw SM, Diltoer M, Spapen HD. Citrate formulation determines filter lifespan during continuous veno-venous hemofiltration: a prospective cohort study. Blood Purif. 2015:40:194-202.

3. Meier-Kriesche HU, Gitomer J, Finkel K, DuBose T. Increased total to ionized calcium ratio during continuous venovenous hemodialysis with regional citrate anticoagulation. Crit Care Med. 2001;29:748-52.

4. Schwarzer P, Kuhn SO, Stracke S, Gründling M, Knigge S, Selleng S, et al. Discrepant post filter ionized calcium concentrations by common blood gas analyzers in CRRT using regional citrate anticoagulation. Crit Care. 2015;19:321

5. Mariano F, Morselli M, Bergamo D, Hollo Z, Scella S, Maio M, et al. Blood and ultrafiltrate dosage of citrate as a useful and routine tool during continuous venovenous haemodiafiltration in septic shock patients. Nephrol Dial Transplant. 2011:26:3882-8.

\footnotetext{
*Correspondence: patrick.honore@az.vub.ac.be

ICU Department, Universitair Ziekenhuis Brussel, Vrije Universiteit Brussel, 101, Laarbeeklaan, 1090Jette, Brussels, Belgium
} 